\title{
Photosynthesis, biomass and fine root growth dynamics of soybean in walnut-soybean agroforestry system
}

Bin Liu

North West A\&F University https://orcid.org/0000-0003-1912-4145

Pengxiang Gao

North West A\&F University

Shuoxin Zhang ( $\nabla 1670167211 @ q q . c o m)$

https://orcid.org/0000-0003-4180-0576

Research article

Keywords: Walnut-soybean, The Loess Plateau, Agroforestry, Photosynthetic, Root growth dynamics

Posted Date: April 28th, 2020

DOI: https://doi.org/10.21203/rs.2.16578/v2

License: (c) (i) This work is licensed under a Creative Commons Attribution 4.0 International License.

Read Full License 


\section{Abstract}

Background:Agroforestry system is regarded as a promising practice in sustainable agricultural management. However, the effects of long-term tree-based intercropping on crop remain poorly understood, especially in the Loess Plateau. In this study, the impacts of photosynthetic and respiration rate were determined by the portable photosynthesis system (Li-6400), and the effects of the root growth dynamics of soybean in walnut-soybean intercropping system were measured by soil auger and WinRHIZO root analysis system, in the Loess Plateau.

Results:The results showed that soybean reached the highest net photosynthetic rate during flowering period, with the net photosynthetic rate of intercropped soybean, which was $20.40 \mu \mathrm{mol} \cdot \mathrm{m}-2 \cdot \mathrm{s}-1$, significantly higher than that of its monocropped counterpart. Soybean biomass reached the maximum during the pod-bearing period, with intercropped soybean biomass being $25.49 \mathrm{~g}$, significantly higher than that of its monocropped counterpart. The mean diameter and increased density of soybean fine roots reduced along with increased soil depth. Both the diameter $(0.43 \mathrm{~mm})$ and increased density $(930 \mathrm{~cm} / \mathrm{dm} 3)$ of intercropped soybean fine roots were evidently higher than those of monocropped soybean $(0.35 \mathrm{~mm}, 780 \mathrm{~cm} / \mathrm{dm} 3)$. With increasing cropping years, fine roots of intercropped soybean tended to be mainly distributed in soil at a depth between 0 and $20 \mathrm{~cm}$ from the fifth year.

Conclusion:Collectively, compared with soybean monoculture, walnut soybean agroforestry system is more conducive to soybean growth in the Loess Plateau.

\section{Background}

The Loess Plateau is the cradle of the Chinese nation and the ancient civilization. As an artificial multispecies vegetation system, the agroforestry system entails different functional organs in the spatial niche, varied functional activity cycles on the temporal dimension, competition adaptability in term of biomorphic function and species distribution patterns on the spatial dimension. Theoretically, these give rise to a composite system. The competition and interplay between different species in a multi-species ecosystem determines the stability and sustainability of the system itself. Considering the potential benefits of tree-based intercropping systems, an appropriate agroforestry system can be a foundation for effective resource utilization. However, in actual applications, the benefits of agroforestry may disappear as tree shades can reduce crop photosynthesis and competition between root systems affect crop's absorption of water and nutrients.

Focusing on the walnut-soybean agroforestry system in the Loess Plateau of China, this paper explores the influence of soybean photosynthesis, as well as the competitive relationship between soybean and walnut root systems in order to provide feasible proposals for constructing highly efficient agroforestry systems and maximally increasing crop yields.

\section{Results}


The most evident difference between intercropped and monocropped soybean lies in a larger competitiveness of intercropped soybean in terms of transpiration rate, net photosynthesis rate and stomatal conductance during the flowering period(Table 1). For both intercropped and monocropped soybean, the transpiration rate, net photosynthesis rate and stomatal conductance increased and then decreased over time, reaching their maximum values during the flowering period.

The biomass of intercropping soybean was significantly heavier than that of monoculture soybean at podding stage(Table 2). At flowering stage, root biomass of intercropping soybean was significantly higher than that of monoculture soybean. For intercropping soybean and monoculture soybean, the fresh weight, dry weight of single plant, biomass of above ground and biomass of under ground of soybean increased with time, and reached the maximum at the podding stage of soybean.

The competition intensity between walnut and soybean decreased with the increase of soil depth(Table 3). In 0-20cm, walnut and soybean roots showed the greatest competition.

The soil moisture content gradually decreases with the increase of soybean growth period and soil depth(Figure 1). At 0-20cm, the moisture content of the walnut-soybean agroforestry system was significantly higher than that of the single-cropping soil at the flowering stage $(P<0.05)$.

Both intercropped and monocropped soybean had only one root growth peak at the soil depth of $0-60 \mathrm{~cm}$, with the peaks being reached basically at the same time (Figure 2). Starting from the 5 th year, intercropped soybean had a significantly greater root growth peak $(P<0.05)$ at $0-20 \mathrm{~cm}$ soil depth than its monocropped counterpart. Starting from the 50th after soybean planting, the monocropped soybean had a significantly greater root growth peak $(P<0.05)$ at $20-60 \mathrm{~cm}$ soil depth than its intercropped counterpart.

There were no significant changes in soybean fine root length densities at 0-60 $\mathrm{cm}$ soil depth with the increasing planting years(Figure 3). The root length density of intercropped soybean at $0-20 \mathrm{~cm}$ soil depth increased with the increasing planting years. Starting from the 5th year, the root length density of intercropped soybean was significantly higher than its monocropped counterpart $(P<0.05)$. The root length density of intercropped soybean at $20-60 \mathrm{~cm}$ soil depth decreased with the increasing cultivation years, and started to be significantly lower than that of the monocropped soybean $(P<0.05)$ from the 7 th year.

The mean fine root diameter of intercropped soybean at 0-20 $\mathrm{cm}$ soil depth was significantly larger than that of the control group(Figure 4). The mean fine root diameter of intercropped soybean during the flowering period was significantly larger than that of the control group $(P<0.05)$, but the same diameter at 20-40 cm soil depth was smaller than that of the monocropped soybean during the sowing period. The mean fine root diameter of intercropped soybean at $40 \mathrm{~cm}$ soil depth was significantly smaller than that of the control group $(\mathrm{P}<0.05)$.

\section{Discussion}


According to the preliminary data published by the General Administration of Customs of China in 2016, soybean imports have exhibited a growing trend over recent years, and soybean is proven to generate more economic benefits than other crops (Peng 2009). To alleviate poverty and soybean import pressure, the Chinese government has started to encourage soybean cultivation among farmers. Exploring the interspecies competitive pressure exerted on soybean in the walnut-soybean agroforestry system is of great significance.

Shading influences crop's net photosynthesis rate and thus its yields. Nurembe (2012) found that the walnut-soybean agroforestry system had a limited shading influence on soybean, which is consistent with our experimental results. A study conducted by Miller (2014) indicated that competition over water resources represented a key factor influencing crop yields in the walnut-soybean agroforestry system. An appropriate level of shading effectively prevents soil moisture evaporation, increases soil moisture concentration, contributes to the increase in net photosynthesis rate and thus improves the biomass of soybean (Luo 1995). Such a conclusion is also supported by the results of this research. According to the study of Zhang (2011), yields of intercropped soybean decreased by $29 \%$ compared with those of monocropped soybean. This may be attributable to the relatively thinner soil layer in Zhang 's experiment site located in the Taihang Mountain region, which can result in unfixed ecological niche of soybean roots and thus higher pressure of interroot competition. Results from this study showed that the walnutsoybean agroforestry system can effectively improve soybean yields.

The growth and root length density peaks of intercropped soybean at 0-20 $\mathrm{cm}$ soil depth were higher than those of its monocropped counterpart, and the growth and fine-root length density peak values of intercropped soybean at 20-60 cm soil depth were lower than its monocropped counterpart, which are consistent with findings of Zhang (2002) and Wang (2011). Yang (2007) argued that root growth was associated with soil moisture, water obtained by soybean from the soil would be predominantly used for root growth, and insufficient soil moisture would stimulate root growth. Interspecies competition between the root systems of a walnut-soybean agroforestry system is quite intense at 0-20 cm soil depth, which stimulates, to some extent, the growth of soybean roots. Guan (2001) and Li (2010) asserted that the walnut-soybean agroforestry system effectively increased the moisture content of the 20-60 cm soil layer, and consequently, the root length density of monocropped soybean would be higher than that of the intercropped soybean at this soil depth. As such, the walnut-soybean agroforestry system can effectively improve the root length density of soybean and increase the crop's absorption and utilization of water from soil.

In a walnut-soybean agroforestry system, soybean root systems could achieve rapid growth within a short period of time, thus gaining an advantage in the interspecies competition. Results from this study showed that with the increasing planting years in a walnut-soybean agroforestry system, the central distribution of roots exhibits a declining trend for walnut and a climbing trend for soybean. The results of this research are consistent with those of Fan (1999), Ma (2009) and Gao (2013). Walnut is reported to produce a secretion called juglone, which is a toxic substance that can affect the growth of maize plants (Jose 2016). The study of walnut juglone by Angel (1993) and Jose (1998) showed that the 
concentration of walnut juglone affected the photosynthetic efficiency of soybean. However, the study of Jose (1998) showed that when the concentration of walnut juglone was lower than 10-6M, the concentration of walnut juglone would not affect the photosynthesis of soybean. The study of $\operatorname{BÖHM}(2006,2010)$ on Walnut juglone to promote the lignification of soybean root system showed that the low concentration of walnut juglone $(<1 \mu \mathrm{M})$ could inhibit the lignification of soybean root system and promote the growth of soybean root system. However, similar result that walnut juglone inhibited the photosynthesis and root growth of soybean has not been found in this research, which may be due to the low concentration of walnut juglone in the soil under field conditions. To sum up, due to the interspecies competition between the root systems in a walnut-soybean agroforestry system, the roots of intercropped soybean tend to be distributed in the $0-20 \mathrm{~cm}$ soil layer. In the 5 th operating year of the walnut-soybean agroforestry system, a unique ecological niche of soybean roots starts to take shape in the soil.

Results from this study showed that the mean diameter of soybean fine roots reaches its maximum value during the flowering period, which may be due to the fact that the flowering season falls in late July when rainfall in the Qishan region reaches its maximum intensity, in the 0-60 cm soil layer. Abundant soil moisture reduces the pressure of interspecies competition between soybean roots (Wang 2007), explaining why the mean diameter of soybean fine roots reaches its maximum value during the flowering period. In the $0-60 \mathrm{~cm}$ soil layer, the mean diameters of both intercropped and monocropped soybean reduce along with the increasing soil depth, which may be due to decreased water and nutrients with the increase in soil depth (Zhang 2002). In the $0-20 \mathrm{~cm}$ soil layer, the mean root diameter of intercropped soybean significantly increases compared with that of its monocropped counterpart. This may be caused by the phenomenon that the remnant pore spaces of walnut roots amid their turnover processes are utilized by soybean roots, and a relatively loose soil environment contributes to the increase of mean diameter of soybean fine roots. These are consistent with findings of Xu (2012) and Wang (2014). In the 40-60 $\mathrm{cm}$ soil layer, the mean root diameter of intercropped soybean is significantly lower than that of its monocropped counterpart. Soybean fine roots are mostly distributed in the 0-20 cm soil layer (Xun 2013). However, a study conducted by Wang (2018) explored the mean fine root diameter of wheat in a walnutwheat agroforestry system, finding that in the $0-60 \mathrm{~cm}$ soil layer, the mean fine root diameter of intercropped wheat is larger than that of its monocropped counterpart. This may be because that the walnut-soybean agroforestry system cannot give rise to a stable ecological niche of roots as the walnutwheat agroforestry system does. Therefore, the smaller mean fine root diameter of intercropped soybean in the 40-60 cm soil layer is a product of a survival strategy adopted by soybean roots in order to cope with the fierce interspecies competition (Sun 2002, Myers 2005, Yan 2013). In short, the walnut-soybean agroforestry system - whose operation originated from late July when interspecies competition was the lowest - can provide favorable soil conditions for roots of intercropped soybean, which further contributes to soybean roots' general water and nutrient absorption from soil in the $0-60 \mathrm{~cm}$ soil layer.

\section{Conclusion}

In conclusion, we argue that with the increasing planting years, a fixed ecological niche for soybean roots will be established in the walnut-soybean agroforestry system. The interspecies competition of soybean 
roots in the walnut-soybean agroforestry system is favorable, to some extent, for root growth, which further facilitates soybean roots in the intercropping system to absorb water from soil, thereby improving soybean yields.

\section{Methods}

Plant materials and site description

The research area is located in the southern part of the Loess Plateau, belonging to the temperate continental monsoon climate. The experimental areas of the study was located in Zhangjiagou village

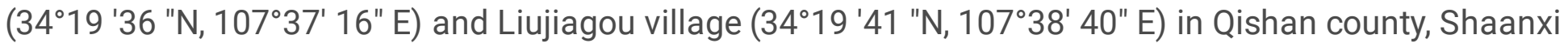
Province. The annual average sunshine hours are $2185 \mathrm{~h}$, the average temperature is $11.6^{\circ} \mathrm{C}$, the extreme maximum temperature is $41.4^{\circ} \mathrm{C}$, the extreme minimum temperature is $-20.6^{\circ} \mathrm{C}$, and the frost-free period is 198 days. The mean annual precipitation is $679 \mathrm{~mm}$, which can basically meet the needs of crop growth. However, due to the influence of monsoon climate, the annual seasonal distribution is not uniform. The precipitation in June to September accounts for about $70 \%$ of the annual precipitation. In the test area, the soil was mainly made of loess mother material, with organic matter content of $2.45 \%$, total nitrogen content of $0.116 \%$ and total phosphorus content of $0.098 \%$ (IUSS 2015).

Soybean is the major crop in the researched area. The crop under tree canopies selected in this research was soybean (Qindou 8). Xiangling, a local walnut variety that is most widely planted in the area, was selected. The walnut trees were planted in 2016 (1a) at $3 \mathrm{~m} \times 6 \mathrm{~m}$ row spacing. The width of soybean alleys was $4.8 \mathrm{~m}$, while that of walnut tree strips was $1.2 \mathrm{~m}$. Soybean was planted on June 6, 2017 at $30 \mathrm{~cm} \star 30 \mathrm{~cm}$ row spacing. The planting density of monocropped soybean was the same as that of its intercropped counterpart. An experimental plot used to measure dynamic changes in root length density of tree seedlings in different planting years was established in 2007, which underwent the same arrangements as in the experimental field described above.

Photosynthetic and respiration rate sampling

On three consecutive sunny days, the net photosynthesis rate (Pn), stomatal conductance (Gs), respiratory rate $(\mathrm{Tr})$ and intercellular $\mathrm{CO}_{2}$ concentration on the second fully expanded leaf of soybean, which were selected during 9:00-11:00 a.m., were measured with the portable photosynthesis system (Li6400; LI-COR Inc., Lincoln, NE, USA).

Soil sampling

Soil Moisture Content 20 sampling points distributed in an s-shaped form were established in the sample plot, where the soil auger was used to obtain samples at the depth of $0-20,20-40,40-60 \mathrm{~cm}$. $100 \mathrm{~g}$ of soil was weighed and place it in the oven at $105 \pm 2^{\circ} \mathrm{C}$ to dry the constant weight $(W)$. Samples were taken during the branching, flowering and pod bearing periods, respectively. 


\section{See formula 1 in the supplementary files.}

Collection and measurement of photosynthetic data

\section{Root sampling}

Root samples were taken with a soil auger. The total sampling depth was $60 \mathrm{~cm}$, with $10 \mathrm{~cm}$ for each layer. Three sampling points distributed in a triangle form, far away from fringe areas, were established in the sample plot. Samples were taken during the branching, flowering and pod bearing periods, respectively.

Soybean fine roots were prepared through soaking, washing and separating procedures. Fine roots with a diameter less than $2 \mathrm{~mm}$ were selected. WinRHIZO root analysis system was applied to obtain the morphological indicators of fine roots, such as root length density and fine root diameter.

After the fixed sample plots were established, a minirhizotron system (BTC-100 Borescope Root Ecology Monitoring System) was employed to carry out in-situ observation of seasonal growth dynamics of roots. Root imaging data were collected every 10 days over an entire growth cycle. Root length parameter was obtained using the Winrhizo-tron-MF to calculate root length density, which was followed by a calculation of fine root length for the observation period.

Pianka(1973) niche overlap formula (symmetric a method) is adopted to calculate the competition intensity index among walnut soybeans, and the formula is shown as follows:

\section{See formula 2 in the supplementary files.}

$A_{i h}=A_{h i}$ and $A_{i h} \leq 1, \mathrm{r}$ is depth of soil layer, and $\mathrm{r} \leq 3, P_{i j}$ and $P_{h j}$ are respectively the proportion of species $i$ ( length density of soybean) or species $h$ ( length density of soybean) using the $j$ (length density of soybean and walnut) resource bit in its utilization of all resource bits. Pianka method is insensitive to the number of individuals of a population or its quantitative characteristics of a population in a community, but it can objectively reflect the extent of niche overlap between populations and the changes of niche overlap relation between populations, and is used to measure the degree of competition of Shared resources among populations under the condition of resource shortage.

The data of the test were analyzed by SAS 8.2 software for variance analysis, and the figures were made by OriginPro9.0 software. On the basis of data analysis, the soil layers discussed were set as 4 soil layers of $0-20,20-40$ and $40-60 \mathrm{~cm}$.

\section{Declarations}

Ethics approval and consent to participate: Not applicable 
Consent for publication: Not applicable

Availability of data and materials: Not applicable

Competing interests: The authors declare that they have no competing interests

Funding: Mr. Shuoxin Zhang, from the University of Northwest A\&F University in China, was the professor of the Academy of Forestry, and was the leader of the project of Resource-saving and Environmental Improvement Agroforestry Composite Technology and Demonstration (2015BAD07B05). The project provided a scholarship and a partial research grant to the first Author (Bin Liu) to complete an PHD degree at the Northwest A\&F University. The project did not provide help for the design of the study and collection, analysis, and interpretation of data and writing the manuscript $\square$

Authors' contributions: BL performed the experiment and data processing, and was a major contributor in writing the manuscript. PX G performed the setting of the experiment plot. SX Z provided valuable suggestions for the design of the experiment. All authors read and approved the final manuscript.

Acknowledgements: We appreciate Yulin Xu at Weiweiyuan Walnut Professional Farmer Cooperative, Qishan County, for his industrious work in governing the sample fields. We thank the editor and anonymous reviewers for their careful revisions and constructive comments.

\section{References}

1. Angel A.M. Hejl, Frank A.Einhellig, James A. Rasmussen (1993). Effects of juglone on growth, photosynthesis, and respiration. Journal of Chemical Ecology. 19,559-568

2. Bohm P.A.F., Bohm F.M.L.Z., Ferrarese M.L.L., Salvador V.H., Soares A.R., Ferrarese-Filho O. (2010). Effects of Juglone on soybean root growth and induction of lignification. Allelopathy Journal. 25(2):465-474

3. BÖHM P.A.F., ZANARDO F.M.L., FERRARESE M.L.L., FERRARESE-FILHO O. (2006). Peroxidase activity and lignification in soybean root growth-inhibition by juglone. BIOLOGIA PLANTARUM 50 (2): 315317, 2006

4. Chen G. P.; Chai Q.; Niu J.Y. (2007). Research on root temporal and spacial distribution of intercropped cereal and legume crops. Acta Agriculturae Boreali-occidentalis Sinica. 16(5):113-117

5. Department of foreign trade and economic statistics, National Bureau of Statistics. (2017). Beijing: China Statistics Press

6. Fan W.; Lu Q.; Gao X.R. (1999). Distribution pattern and growing dynamics of the roots system in apple-wheat intercropping system. Acta Ecologica Sinica. 19(6):860-863

7. Gao L.B.; Xu H.S.; Bi H.X.; Xi W.M.; Bao B.; Wang X.Y.; Bi C.; Chang Y.F. (2013) Intercropping competition between apple trees and crops in agroforestry system on the Loess Plateau of China. PLoS One. 8(7): e70739 
8. Guan X.J.; Zhao S.W.; Wang J.Z.; Li B.C. (2001). Effects of water deficits on roots and crown of winter wheat during its different development stages. Acta agriculture boreali-sinica. 16(4): 71-76

9. IUSS Working Group WRB. (2015). World Reference Base for Soil Resources 2014, Update 2015. International Soil Classification System for Naming Soils and Creating Legends for Soil Maps; World Soil Resources Reports No. 106; FAO: Rome, Italy.

10. Jose S; Gillespie AR; Seifert JR; Biehle DJ. (2016) Defining competition vectors in a temperate alley cropping system in the mid-western USA. 2. Competition for water. Agrofor Syst 48:41-59. doi:10.1023/A:1006289322392

11. Li Bo. (2000). Ecology. Beijing: Higher Education Press.208-211

12. Li J.Y.; Fu B.C.; Ma Y.C. (2006). A review of researches and methods for fine-root production and turnover of trees. Journal of Shanxi Agriculture University. 26(5): 1-6

13. Li Q.Q.; Dong B.D.; Qiao Y.Z.; Liu M.Y.; Zhang J.W. (2010). Root growth available soil water , and wateruse efficiency of winter wheat under different irrigation regimes applied at different growth stages in North China. Agricultural Water Management. 97(10):1676-1682

14. Luo W-X (1995) Study on construction model of eco-economical type protection forest system on WeiBei of Loess Plateau. Chinese Forestry Press, Beijing

15. Ma C.M.; Zhuo M.P.; Liu C.P. (2009) Root distribution characteristics of Juglans regia in monoculture and intercropping. Journal of Beijing Forestry University. 31(6): 181-186

16. Miller AW, Pallardy SG (2010) Resource competition across the crop-tree interface in a maize-silver maple temperate alley cropping stand in Missouri. Agroforestry Systems 3:247- 259. doi:10.1023/A:1013327510748

17. Myers DB $₫(2005) \llbracket$ Soybean root distribution in claypan soils (MS thesis) $\llbracket$ Columbia: University of

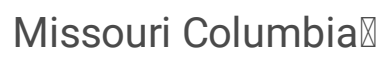

18. Namirembe S (1999) Tree management and resource utilization in agroforestry systems with Senna spectabilis in the drylands of Kenya. Ph.D. Thesis, University of Wales, Bangor, 206 pp

19. Ong C.K.; Corlett J.E.; Singh R.P.; Black C.R. (1991). Above and below ground interactions in agroforestry systems. Forest Ecology and Management. 45(1/4): 45-57

20. Peng X.B.; Zhang Y.Y.; Cai J.; Jiang Z.M.; Zhang S.X. (2009). Photosynthesis,growth and yield of soybean and maize in a tree-based agroforestry intercropping system on the Loess Plateau. Agroforestry System.76: 569-577

21. Pianka ER. (1973). The structure of lizard communities. Annual Review of Ecology and Systematics, 4:53-74】

22. Shibu Jose, Andrew R.Gillespie. (1998). Allelopathy in black walnut(Juglans nigra L.) alley cropping.II.Effects of juglone on hydroponically grown corn( Zea mays L.) and soybean( Glycine max L.Merr.) growth and physiology. Plant and Soil. 203:199-205

23. Simpson JA .(1999). Effects of shade on corn and soybean productivity in a tree based intercrop system. M.Sc. Thesis. University of Guelph, Guelph 
24. Sun G.Y.; Zhang R.H.; Huang Z.W. (2002). Soybean root distributions in meadow-blackland and albicsoil. Chinese Journal of Oil Crop Sciences. 24(1): 45-47

25. Sun S.J.; Sang Y.Q.; Meng P.; Zhang J.S.; Jia C.R.; Ren Y.F. (2011). Spatiotemporal distribution and edge effects of intercropping winter wheat root in low mountain and bill regions of North China. Journal of Henan Agriculture University. 45(6): 640-646

26. Tsonkova, P.; Quinkenstein, A.; Freese, D. (2012). Ecological benefits provided by alley cropping systems for production of woody biomass in the temperate region: A review. Agroforestry. Systems. $85,133-152$.

27. Vogt KA, Moore EE, Vogt DJ, et al. (1983). Conifer fine root and mycorrhizal root biomass within the forest floor of Doug las-fir stand soil different ages and site productivities. Canadian Journal of Forest Research, 13:429-437

28. Wang B.J.; Zhang W.; Ahanbieke P.; Gan Y.W.; Xu W.L.; Li L.H.; Christie P.; Li L. (2014). Interspecific interactions alter root length density, root diameter and specific root length in jujube/wheat agroforestry system. Agroforestry Systems. 88(5): 835-850

29. Wang L.; Gao P.X.; Zhong C.G.; Liu B.; Hou L.; Zhao Y.J.; Zhang S.X.; Zhang Y.Y. (2018). Growth dynamics and competitive strategies of fine roots in a walnut-wheat agroforestry system. Acta Ecologica Sinica. DOI: 10.5846/stxb201709021587

30. Xun H.S.; Bi H.X.; Gao L.B.; Yun L.; Chang Y.F.; Xi W.M.; Liao W.C.; Bao B.(2013). Distribution and morphological variation of fine root in a walnut-soybean intercropping system in the Loess Plateau of China. International Journal of Agriculture \& Biology. 15: 998-1002

31. Xun H.S.; Gao L.B.; Bi H.X.; Yun L.; Bao B. (2012). Fine root distribution and underground competition in walnut-soybean intercropping system. Chinese Journal of Ecology. 31(7): 1612-1616

32. Yan C.J.; Wang W.B.; Tu X.J.; Wang C.L.; Zhang L.J.; Du Z.; Song S.H. (2013). Effect of drought stress at different growth stage on yield and root characteristics of soybean. Soybean science. 32(1): 5967

33. Yang S.Y.; Yan P.; Mei X.Y.; Sun X.B. (2007). Effects of different soil water deficits on roots of winter wheat. Journal of Triticeae Crops. 27(2): 309-313

34. Zhang J.S.; Meng P.; Yin C.J.; Ma X.Q.; Feng W.D. (2002). Spatial and temporal distribution characteristics of wheat roots in apple-wheat intercropping. Forest Research. 15(5): 537-541

35. Zhang JS, Meng P, Xin XB, Yin CJ. (2011). Effects of appleginger inter-cropping in the hilly land of Taihang Mountain. Sci Silvac Sin 37(2):74-78

36. Zhang J-T. (2010). The relationship between environmental decline and the destruction of vegetation in Loess Plateau. J Shanxi Univ (Nat Sci Ed), (Suppl.) 37-41

37. Zhu QK, Zhu JZ. (2013). Study on niche of agroforestry systems in the Loess Plateau. Journal of soil and water conservation. 1(1):49-52

\section{Tables}


Table 1 The photosynthetic factors of soybean

\begin{tabular}{|c|c|c|c|c|c|}
\hline \multicolumn{2}{|c|}{ Measurement } & $\begin{array}{c}\text { Transpiration } \\
\text { rate } \\
\left(\mathrm{m} \mathrm{mol} \cdot \mathrm{m}^{\square 2} \cdot \mathrm{s}^{\square 1}\right)\end{array}$ & $\begin{array}{l}\text { Net photosynthesis rate }\left(\mu \mathrm{mol} \cdot \mathrm{m}^{\square 2} \text {. }\right. \\
\qquad \mathrm{s}^{\square 1_{\square}}\end{array}$ & $\begin{array}{c}\text { Stomatal } \\
\text { conductance } \\
\square \mathrm{mol} \mathrm{m} \cdot{ }^{\square 2} \mathrm{~s} \cdot{ }^{\square 1_{\square}}\end{array}$ & $\begin{array}{c}\text { Intercellular } \\
\mathrm{CO}_{2} \text { concentration } \\
\left(\mu \mathrm{L}^{\square 1}\right)\end{array}$ \\
\hline Branching & $\mathrm{CK}$ & $1.43 \mathrm{a}$ & $12.94 \mathrm{a}$ & $155.18 \mathrm{a}$ & $106.94 \mathrm{a}$ \\
\hline & $\mathrm{T}$ & $1.29 \mathrm{ab}$ & $14.94 \mathrm{a}$ & $172.24 \mathrm{a}$ & $93.31 \mathrm{a}$ \\
\hline Flowering & CK & $4.29 \mathrm{a}$ & $16.93 \mathrm{a}$ & $187.40 \mathrm{a}$ & $195.44 a$ \\
\hline & $\mathrm{T}$ & $3.43 \mathrm{~b}$ & $20.40 \mathrm{~b}$ & $212.36 \mathrm{~b}$ & $188.14 \mathrm{ab}$ \\
\hline Podding & CK & $2.92 \mathrm{a}$ & $15.63 \mathrm{a}$ & $178.26 \mathrm{a}$ & $263.72 \mathrm{a}$ \\
\hline & $\mathrm{T}$ & $2.29 \mathrm{ab}$ & $16.31 \mathrm{ab}$ & $189.31 \mathrm{a}$ & $213.24 b$ \\
\hline
\end{tabular}

The data in the table are the mean value of different treatments. The letter after data expression Duncan's multiple comparison results. Those date in the same column with the same letter indicate there is no significant difference $(\mathrm{P}>0.05)$.

Table 2 The biomass of soybean

\begin{tabular}{|c|c|c|c|c|c|}
\hline \multicolumn{2}{|c|}{ Measurement } & $\begin{array}{l}\text { Fresh weight of single plant } \\
\text { (g) }\end{array}$ & $\begin{array}{l}\text { Biomass of above ground } \\
\text { (g) }\end{array}$ & $\begin{array}{l}\text { Biomass of } \\
\text { under } \\
\text { ground }(\mathrm{g})\end{array}$ & $\begin{array}{c}\text { Dry weight of single plant } \\
\text { (g) }\end{array}$ \\
\hline \multirow[t]{2}{*}{ Branching } & CK & $10.43 \mathrm{a}$ & $2.18 \mathrm{a}$ & $0.70 \mathrm{a}$ & $2.83 \mathrm{a}$ \\
\hline & $\mathrm{T}$ & $10.49 \mathrm{a}$ & $2.20 \mathrm{a}$ & $0.71 \mathrm{a}$ & $2.94 \mathrm{a}$ \\
\hline \multirow[t]{2}{*}{ Flowering } & CK & $26.16 \mathrm{a}$ & $4.73 \mathrm{a}$ & $1.17 \mathrm{a}$ & $5.90 \mathrm{a}$ \\
\hline & $\mathrm{T}$ & $29.72 \mathrm{ab}$ & $5.02 \mathrm{ab}$ & $1.67 \mathrm{~b}$ & $6.68 a b$ \\
\hline \multirow[t]{2}{*}{ Podding } & CK & $65.09 a$ & $16.14 \mathrm{a}$ & $5.24 \mathrm{a}$ & 21.39a \\
\hline & $\mathrm{T}$ & $74.76 \mathrm{ab}$ & $18.65 b$ & $6.83 \mathrm{~b}$ & $25.49 b$ \\
\hline
\end{tabular}

The data in the table are the mean value of different treatments. The letter after data expression Duncan's multiple comparison results. Those date in the same column with the same letter indicate there is no significant difference $(\mathrm{P}>0.05)$.

$\mathrm{T}$ (walnut-soybean) CK (soybean)

Table 3 The competition between the root of walnut and soybean in agroforestry system

\begin{tabular}{llll}
\hline Soil depth & $0-20 \mathrm{~cm}$ & $20-40 \mathrm{~cm}$ & $40-60 \mathrm{~cm}$ \\
\hline Root density walnut & $75.632 \pm 0.515$ & $40.735 \pm 0.273$ & $17.256 \pm 0.209$ \\
$\mathrm{~cm} / \mathrm{dm}^{3} \quad$ soybean & $4317.235 \pm 2.749$ & $694.317 \pm 1.416$ & $601.403 \pm 1.037$ \\
Competition intensity index & $0.637 \pm 0.026 \mathrm{~A}$ & $0.386 \pm 0.033 \mathrm{~B}$ & $0.215 \pm 0.013 \mathrm{C}$ \\
\hline
\end{tabular}

The data in the table are the mean value of different treatments. The letter after data expression Duncan's multiple comparison results. Those date in the same column with the different letter indicate there is significant difference $(\mathrm{P}<0.05)$.

Figures 

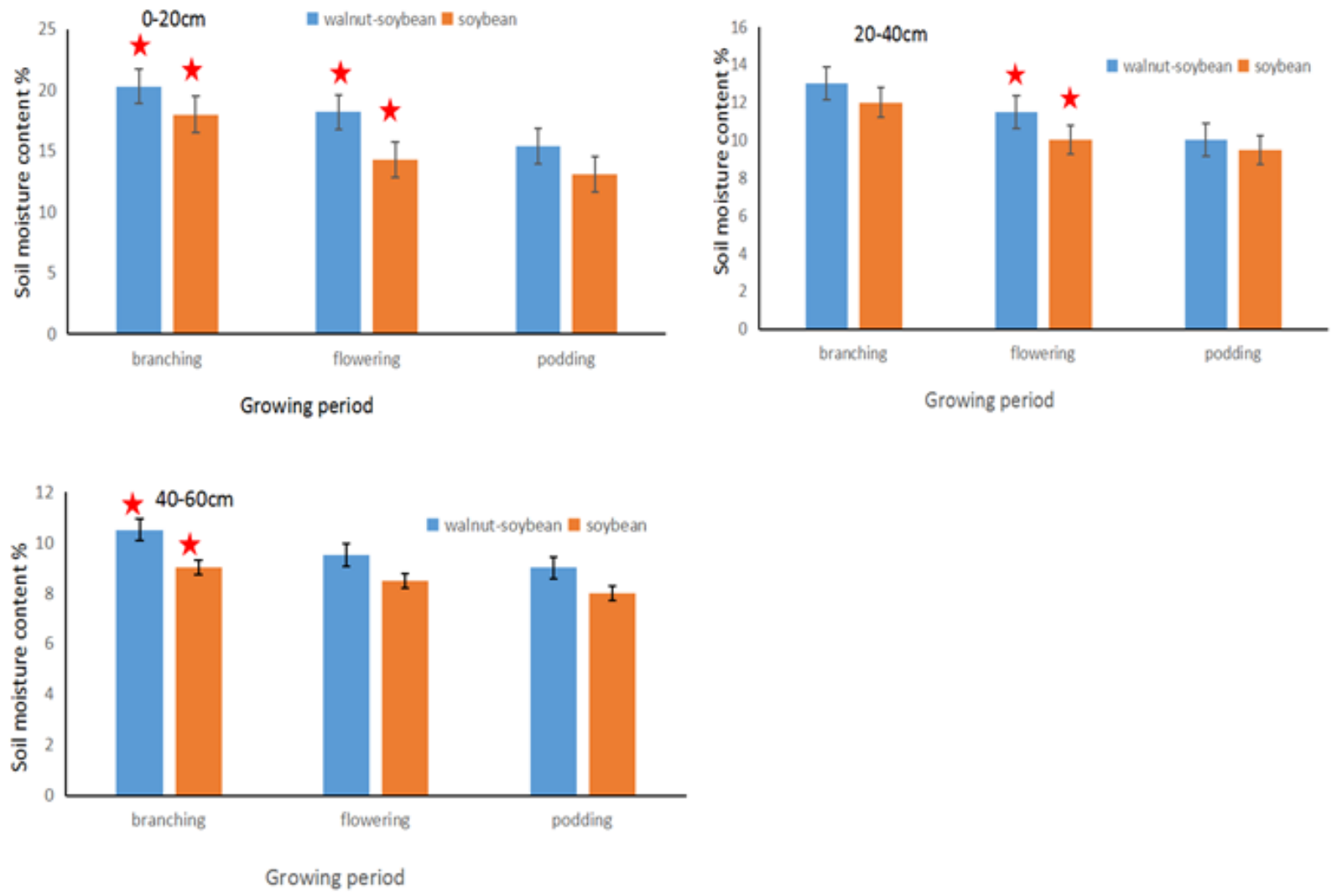

\section{Figure 1}

The relative soil moisture content at different growth stages, different soil depths and different tillage methods. The same asterisk indicates that, through variance analysis, the age of agriculture and forestry compound has a significant influence, $p<0.05$. 

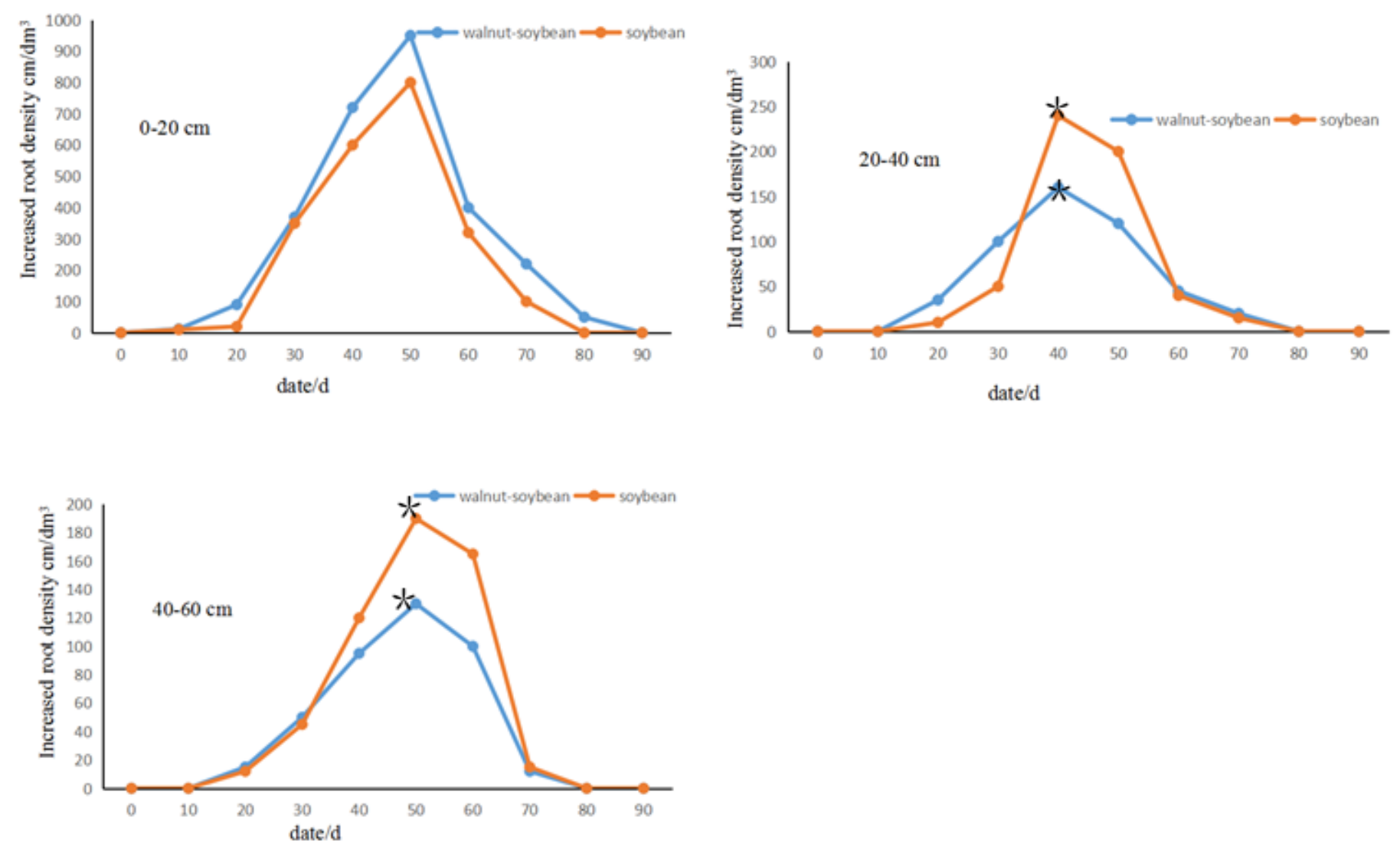

Figure 2

The relative density of increased root in soybean under different growing period, different soil depth and different tillage mode. Asterisks indicate that the effect of agroforestry age is significant through ANOVA at $p<0.05$. 

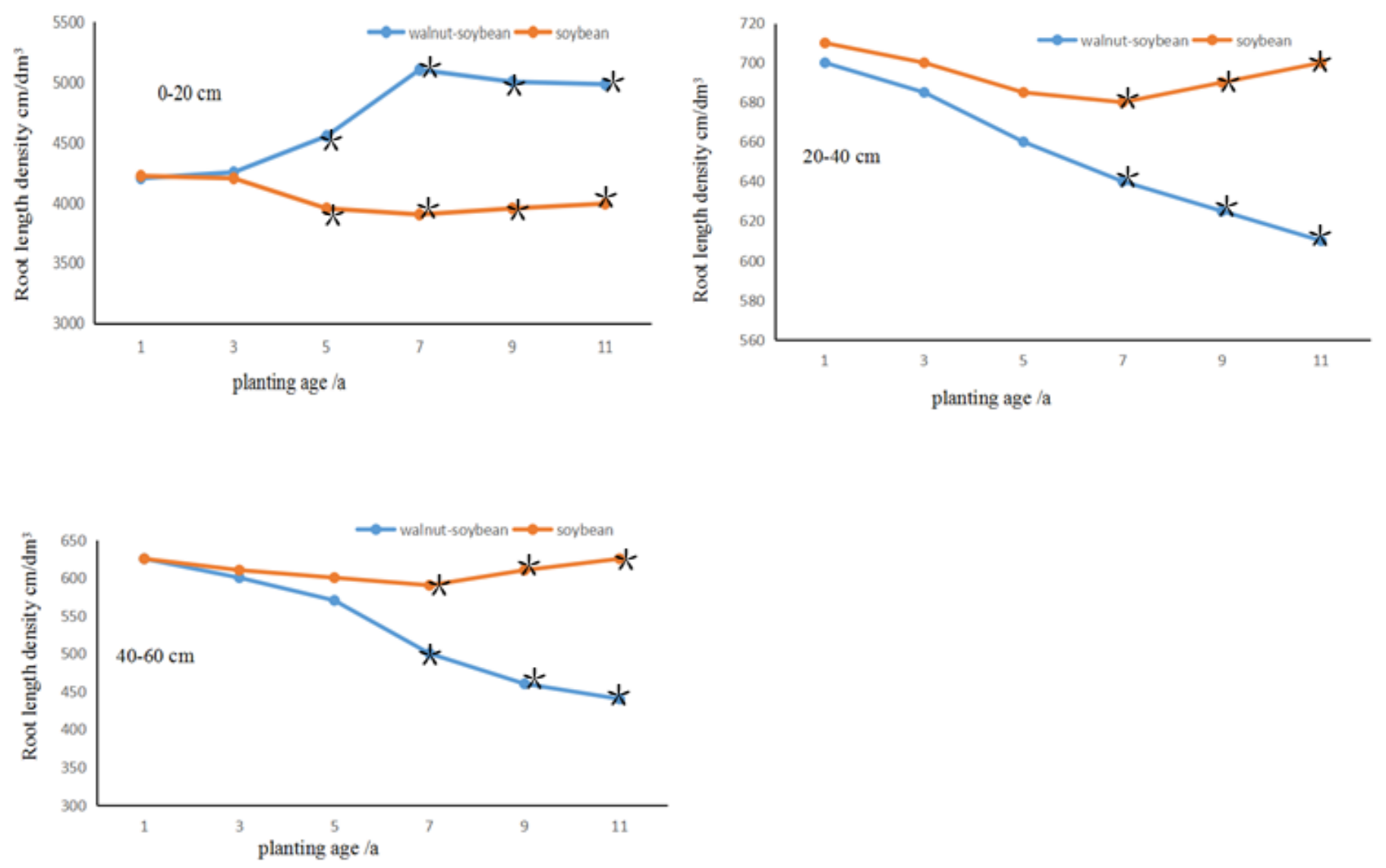

\section{Figure 3}

The relative density of soybean root under different growing period, different soil depth and different tillage mode. Asterisks indicate that the effect of agroforestry age is significant through ANOVA at $\mathrm{p}<0.05$. 

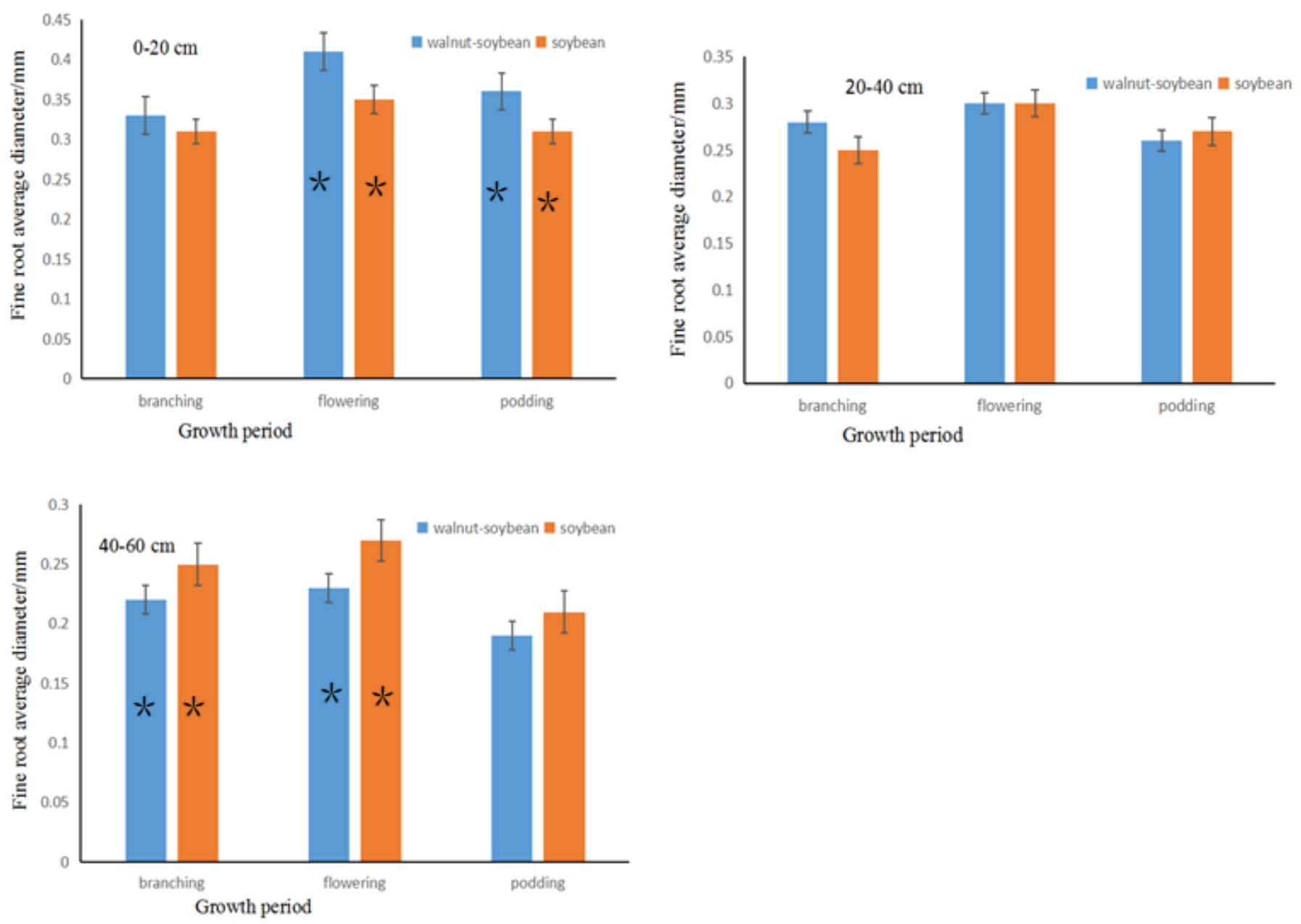

Figure 4

The relative average diameter of thin root in soybean under different growing period, different soil depth and different tillage mode. Asterisks indicate that the effect of agroforestry age is significant through ANOVA at $p<0.05$.

\section{Supplementary Files}

This is a list of supplementary files associated with this preprint. Click to download.

- formulas.docx 